\title{
An Effective System to Detect Fake Research
}

\author{
R. Mounika, Kayiram Kavitha, R V. S. Lalitha
}

\begin{abstract}
Detection of spam review is an important operation for present e-commwebsites and apps. We address the issue on fake review detection in user reviews in e-commerce application, which wasimportant for implementing anti-opinion spam.First we analyze the characteristics of fake reviews and we apply the machine learning algorithms on that data. Spam or fake reviews of the itemsreducing the reliability of decision making and competitive analysis.The presence of fake reviews makes the customer cannot make the right decisions of sellers, which can also causes the goodwill of the platform decreased. There is a chance of leaving appraisals via web-based networking media systems whether states or harming by spammers on specific item, firm alongside their answers by recognizing these spammers just as in like manner spams so as to understand the assessments in the interpersonal organizations sites, we exist a stand-out structure called Netspam which uses spam highlights for demonstrating tribute datasets as heterogeneous subtleties systems to guide spam location treatment directly into gathering issue in such systems.
\end{abstract}

Index Terms: System Spam, online informal organizations, online web based life.

\section{INTRODUCTION}

A social spam message is possibly observed by everyone in these days in all ecommerce websites. Additionally also worse, it can activate misdirection along with a misconception in public as well as additionally trending subject discussions. These research studies this way have in fact come to be a vital think about the development of solution while desirable audits can bring benefits for a business, unfavorable research studies can probably influence reliability what's a lot more, develop monetary misfortune. The manner by which anybody with any sort of kind of character can leave comments as review supplies an appealing open entryway for spammers to include fake reviews planned to misdirect customers' thought. These misleading reviews destined to that component repeated by the sharing limit of online long range interpersonal communication just as moreover development on the web. The looks into considered change customers' comprehension of accurately exactly how incredible a point or observing are treating as spam notwithstanding are frequently included in kind for money advance As showed up in [1], 20\% of the exploration thinks about in the Yelp site are on the whole factors considered spam research ponders. In any case, a great deal of composing has truly been disseminated on the frameworks used to perceive spam notwithstanding spammers notwithstanding furthermore amazing sort of

Revised Manuscript Received on October 15, 2019.

R. Mounika, PG Student, Dept. of CSE, Gokaraju Rangaraju Institute of Engineering and Technology, Bachupally, Hyderabad, Telangana, India.

Dr. Kayiram Kavitha, Associate Professor, Dept. of CSE, Gokaraju Rangaraju Institute of Engineering and Technology, Bachupally, Hyderabad, Telangana, India.

Dr. R.V.S.Lalitha, Professor, Dept. of CSE, Aditya College of Engineering, Surampalem, Kakinada, A P, India. appraisal regarding this matter to evaluate the proposed methodology, we utilized 2 tasting research datasets from Yelp alongside Amazon.com sites. Due to our understandings, perceiving 2 points of view for features (inquire about customer besides, social phonetic), the orchestrated features as assessment conduct have unmistakably more loads alongside produce much better execution on deciding spam reviews in both semi-oversaw just as furthermore not being seen strategies. As the impact of this weighting action, we can utilize many less features with significantly more loads to improve the accuracy with much substantially less time a few sided choice. Moreover, purchasing features in 4 real programs (look into study conduct, purchaser conduct, tribute etymological, customer phonetic), urges us to see basically exactly how much every grouping of features are added to spam proposal

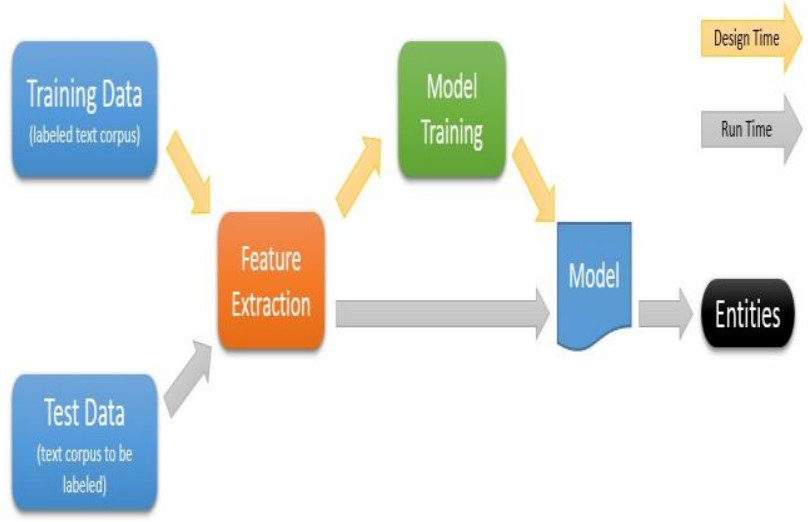

Online Social media websites play a prominent function in careful expansion. So, this is considered as an essential source for makers in their marketing campaign along with customers in selecting services or product.

\section{RELATED WORK}

In an academia, [9] study observes the activities of spam reviewers in Twitter, in addition to uncover that the activities of spammers are numerous from real people in the location of posting tweets, followers, following buddies etc [10] much better looks at spammer trademark with making a choice of nectar profiles in 3 gigantic interpersonal organizations arrange sites (Facebook, Twitter notwithstanding Myspace) just as in like manner recognizes 5 ordinary characteristics (followee-to-devotee, WEB LINK rate, message closeness, message sent, companion number, and then some) open door for spammer identification. By the by, albeit both of 2 methodologies existing convincible structure for spammer recognition, they don't have broad strategies needs notwithstanding form assessment.

In [8] authors handle a rotating technique, which mistreats the burstiness principle of analyses to distinguish testimonial 
spammers. Impacts of reviews can be either as a result of unexpected importance of things or spam attacks. Specialists notwithstanding exploration studies appearing in a burst are as often as possible associated as in spammers will in general handle various spammers just as furthermore legitimate to points of interest authorities tends to appear together with changed other authentic to preferences specialists. This sets yourself up for us to make an arrangement of specialists appearing in different ruptureds.

In [9], exploration is a stage in advance in boosting the precision of determining abnormality in an information chart speaking with availability in between individuals in an online social firm. The advised mix strategies rely on cozy tools uncovering strategies using unique type of sustaining information highlights. The techniques are revealed inside a multi-layered structure which provides the total needs expected to revealing problems in information charts created from online social firms, containing information showing as well as likewise an evaluation, keeping in mind, as well as additionally assessment.

In [10] authors misuse tools figuring out techniques to recognize research spam. Around conclusion, actually, create a spam accumulation from slipped audits. At first, research the impact of numerous highlights in spam separating proof. It additionally saw that the testimonial spammer precisely composes spam. This supplies an extra view to recognize audit spam: it can determine if the designer of the research is a spammer.

In [6] authors suggested a distinct idea of a heterogeneous testimonial chart to record the web links among experts, examinations as well as additionally stores that the specialists have in fact checked out. Right below check out specifically just how communications in between facilities in this design can disclose the element for spam as well as additionally recommend a recurring style to distinguish suspicious experts. This is the preliminary go via such unsure web links have really been determined for research study spam location.

\section{PROBLEM DEFINITION}

Detection of spam review is an important operation for present e-commwebsites.We address the issue on fake review detection in user reviews in e-commerce application, which is important for implementing anti-opinion spam.First we analyze the properties of fake reviews and we apply the machine learning algorithms on that data. Spam or fake reviews of the products reducing the reliability of both decision making and market analysis. The presence of fake reviews makes the customer cannot make the right decisions of sellers, which can also causes the goodwill of the platform decreased. So its need of finding solution for detection of spam reviews.

Implementation comprises of various technologies used, installation of required software and libraries, architecture diagram of the project, architecture diagrams of various models, algorithm of the prime model used and sample coding of the project.

\section{IMPLEMENTATION}

Raw data collection and pre processing
Feature creation and label generation

Implement the ML Algorithmi.e.,Naive Bayes and Decision Tree Classifiersand SVM

Validate the results

In this venture we are utilizing MLalgorithms called Naive Bayes,SVM and Decision Tree. Bayes classifiers are a group of straightforward "probabilistic classifiers" in view of applying Bayes' hypothesis with solid (gullible) autonomy presumptions between the highlights.

\section{Naive Bayes Classifier:}

Credulous Bayes classifier accepts that the impact of a specific element in a class is free of different highlights. For instance, an advance candidate is attractive or not relying upon his/her pay, past credit and exchange history, age, and area. Regardless of whether these highlights are associated, these highlights are as yet considered freely. This supposition improves calculation, and that is the reason it is considered as credulous. This supposition that is called class contingent autonomy.

$$
\mathrm{P}(\mathrm{A} / \mathrm{B})=\mathrm{P}(\mathrm{B} / \mathrm{A}) * \mathrm{P}(\mathrm{A}) / \mathrm{P}(\mathrm{B})
$$

A classifier is an ML model that is utilized to separate various articles dependent on specific highlights. A Naive Bayes classifier is a probabilistic ML model that is utilized for order task. The core of the classifier depends on the Bayes hypothesis.

Utilizing Bayes hypothesis, we can discover the likelihood of An event, given that B has happened. Here, B is the proof and An is the theory. The suspicion made here is that the indicators/highlights are free. That is nearness of one specific component doesn't influence the other. Henceforth it is called innocent.

\section{Decision Tree Classifier:}

Choice Tree is a white box kind of ML calculation. It shares inner basic leadership rationale, which isn't accessible operating at a profit box kind of calculations, for example, Neural Network. Its preparation time is quicker contrasted with the neural system calculation. The time intricacy of choice trees is an element of the quantity of records and number of characteristics in the given information. The choice tree is a dispersion free or non-parametric technique, which doesn't rely on likelihood conveyance suspicions. Choice trees can deal with high dimensional information with great precision.

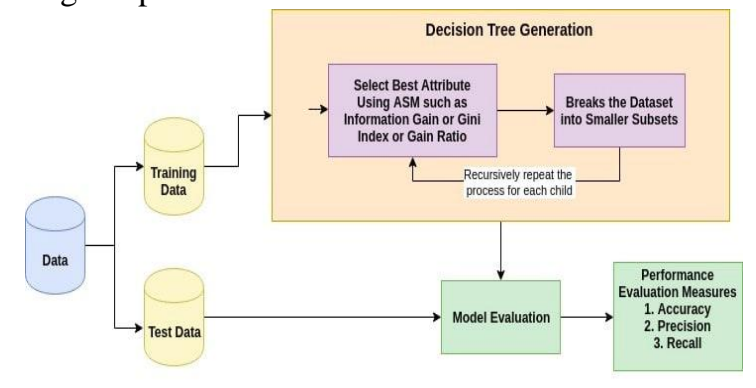

\section{V.SVM}

Support Vector Machineis a supervised learning technique. When we have a dataset with features \& class labels both then we can use svm. But if in our dataset do not have class labels or 
outputs of our feature set then it is considered as an unsupervised learning algorithm. In that case, we can use Support Vector Clustering.

\section{RESULTS AND DISCUSSIONS}

Our dataset is taken from Non-spam hotel reviews by TripAdvisor and Spam reviews by Amazon Mechanical Turk. Dataset consists 20 hotels in Chicago area and size is $1.6 \mathrm{mb}$. Total number of reviews collected is 1600 and 80 reviews per hotel. It consists 40 spam reviews and 40 non spam reviews per hotel.This set consists both positive and negative reviews. This data corpus contains 400 truthful positive reviews from tripadvisor, 400 deceptive positive reviews from mechanical turk, 400 truthful negative reviews from expedia,hotels.com,tripadvisor,yelp and 400 deceptive negative reviews from mechanical turk.

First we are loading total hotel dataset into SQLite database and then we implemented Linguistic and POS features generator over the dataset. The linguistic model works averagely well and the results are shown in Table.

\begin{tabular}{|c|c|c|c|c|}
\hline Approach & $\begin{array}{l}\text { Features } \\
\text { Considered }\end{array}$ & $\begin{array}{l}\text { Train } \\
\text { set } \\
\text { size ( } \\
\text { in\%) }\end{array}$ & $\begin{array}{l}\text { Classifier } \\
\text { used }\end{array}$ & $\begin{array}{l}\text { Accuracy } \\
(\%)\end{array}$ \\
\hline \multirow{9}{*}{$\begin{array}{l}\text { Linguistic } \\
\text { Features }\end{array}$} & \multirow{9}{*}{$\begin{array}{l}\text { Linguistic } \\
\text { Features } \\
\text { vector }\end{array}$} & \multirow[t]{3}{*}{70} & $\begin{array}{l}\text { Naïve } \\
\text { Bayes }\end{array}$ & 72.04 \\
\hline & & & SVM & 72.1 \\
\hline & & & $\begin{array}{l}\text { Decision } \\
\text { tree }\end{array}$ & 64.60 \\
\hline & & \multirow[t]{3}{*}{80} & $\begin{array}{l}\text { Naïve } \\
\text { Bayes }\end{array}$ & 73.25 \\
\hline & & & SVM & 73.25 \\
\hline & & & $\begin{array}{l}\text { Decision } \\
\text { tree }\end{array}$ & 69.00 \\
\hline & & \multirow[t]{3}{*}{90} & $\begin{array}{l}\text { Naïve } \\
\text { Bayes }\end{array}$ & 74.02 \\
\hline & & & SVM & 70.89 \\
\hline & & & $\begin{array}{l}\text { Decision } \\
\text { tree }\end{array}$ & 73.2 \\
\hline
\end{tabular}

Its a result of POS features implementation.

\begin{tabular}{|c|c|c|c|c|}
\hline Approach & $\begin{array}{l}\text { Features } \\
\text { Considered }\end{array}$ & $\begin{array}{l}\text { Train } \\
\text { set } \\
\text { size }( \\
\text { in } \%)\end{array}$ & $\begin{array}{l}\text { Classifier } \\
\text { used }\end{array}$ & $\begin{array}{l}\text { Accuracy } \\
(\%)\end{array}$ \\
\hline \multirow{9}{*}{$\begin{array}{l}\text { POS } \\
\text { Features }\end{array}$} & \multirow{9}{*}{$\begin{array}{l}\text { POS Features } \\
\text { vector }\end{array}$} & \multirow[t]{3}{*}{70} & $\begin{array}{l}\text { Naïve } \\
\text { Bayes }\end{array}$ & 68.6 \\
\hline & & & SVM & 63.8 \\
\hline & & & $\begin{array}{l}\text { Decision } \\
\text { tree }\end{array}$ & 66.6 \\
\hline & & \multirow[t]{3}{*}{80} & $\begin{array}{l}\text { Naïve } \\
\text { Bayes }\end{array}$ & 67.75 \\
\hline & & & SVM & 62.25 \\
\hline & & & $\begin{array}{l}\text { Decision } \\
\text { tree }\end{array}$ & 71.11 \\
\hline & & \multirow[t]{3}{*}{90} & $\begin{array}{l}\text { Naïve } \\
\text { Bayes }\end{array}$ & 72.89 \\
\hline & & & SVM & 66.52 \\
\hline & & & $\begin{array}{l}\text { Decision } \\
\text { tree }\end{array}$ & 68.5 \\
\hline
\end{tabular}

Here its showing n-gram features accuracy.

\begin{tabular}{|l|l|l|l|l|}
\hline Approach & $\begin{array}{l}\text { Features } \\
\text { Considered }\end{array}$ & $\begin{array}{l}\text { Train } \\
\text { set } \\
\text { size ( } \\
\text { in\%) }\end{array}$ & $\begin{array}{l}\text { Classifier } \\
\text { used }\end{array}$ & $\begin{array}{l}\text { Accuracy } \\
(\%)\end{array}$ \\
\hline
\end{tabular}

\begin{tabular}{|c|c|c|c|c|}
\hline \multirow{9}{*}{$\begin{array}{l}\text { n-gram } \\
\text { Features }\end{array}$} & \multirow{9}{*}{$\begin{array}{l}\text { n-gram } \\
\text { Features } \\
\text { vector }\end{array}$} & \multirow[t]{3}{*}{70} & $\begin{array}{l}\text { Naïve } \\
\text { Bayes }\end{array}$ & 73.33 \\
\hline & & & SVM & 73.65 \\
\hline & & & $\begin{array}{l}\text { Decision } \\
\text { tree }\end{array}$ & 72.6 \\
\hline & & \multirow[t]{3}{*}{80} & $\begin{array}{l}\text { Naïve } \\
\text { Bayes }\end{array}$ & 72.7 \\
\hline & & & SVM & 76.11 \\
\hline & & & $\begin{array}{l}\text { Decision } \\
\text { tree }\end{array}$ & 73.62 \\
\hline & & \multirow[t]{3}{*}{90} & $\begin{array}{l}\text { Naïve } \\
\text { Bayes }\end{array}$ & 96.5 \\
\hline & & & SVM & 88.5 \\
\hline & & & $\begin{array}{l}\text { Decision } \\
\text { tree }\end{array}$ & 96.65 \\
\hline
\end{tabular}

\begin{tabular}{|l|l|l|}
\hline n-gram & Classifier & Accuracy \\
\hline Bigram & Naïve Bayes & 73.5 \\
\hline Bigram & SVM & 63.75 \\
\hline Bigram & Decision tree & 73.5 \\
\hline Unigram+Bigram & Naïve Bayes & 71.1 \\
\hline Unigram+Bigram & SVM & 60.01 \\
\hline Unigram+Bigram & Decision tree & 71.83 \\
\hline
\end{tabular}

We are finding sentiment score and linguistic score

\begin{tabular}{|l|l|l|}
\hline Features Used & Classifier & Accuracy \\
\hline $\begin{array}{l}\text { Sentiment Score + } \\
\text { Linguistic }\end{array}$ & Naïve Bayes & 74.5 \\
\hline $\begin{array}{l}\text { Sentiment Score + } \\
\text { Linguistic }\end{array}$ & SVM & 72.02 \\
\hline $\begin{array}{l}\text { Sentiment Score + } \\
\text { Linguistic }\end{array}$ & Decision tree & 75.8 \\
\hline $\begin{array}{l}\text { Sentiment Score + } \\
\text { POS }\end{array}$ & Naïve Bayes & 72.5 \\
\hline $\begin{array}{l}\text { Sentiment Score + } \\
\text { POS }\end{array}$ & SVM & 70.02 \\
\hline $\begin{array}{l}\text { Sentiment Score + } \\
\text { POS }\end{array}$ & Decision tree & 75.7 \\
\hline $\begin{array}{l}\text { Sentiment Score + } \\
\text { Ling + POS }\end{array}$ & Naïve Bayes & 78.9 \\
\hline $\begin{array}{l}\text { Sentiment Score + } \\
\text { Ling + POS }\end{array}$ & SVM & 74.5 \\
\hline $\begin{array}{l}\text { Sentiment Score } \\
+ \text { Ling + POS }\end{array}$ & Decision tree & 76.6 \\
\hline
\end{tabular}

Next Creation of Training and Test dataset as well as feature vector creator, Naive Bayes, SVM and Decision Tree classifiers along with accuracy, confusion matrix, recall, precision and f1score calculation

\begin{tabular}{|l|l|l|l|l|}
\hline Sno & $\begin{array}{l}\text { Accuracy } \\
\%\end{array}$ & $\begin{array}{l}\text { Precision } \\
\%\end{array}$ & $\begin{array}{l}\text { Recall } \\
\%\end{array}$ & $\begin{array}{l}\text { Fscore } \\
\%\end{array}$ \\
\hline $\begin{array}{l}\text { Decision } \\
\text { Tree }\end{array}$ & 95.04 & 92.0 & 95.83 & 93.87 \\
\hline $\begin{array}{l}\text { Naivebaye } \\
\text { s }\end{array}$ & 95.59 & 92.16 & 97.01 & 94.52 \\
\hline SVM & 94.90 & 91.66 & 95.84 & 93.69 \\
\hline
\end{tabular}




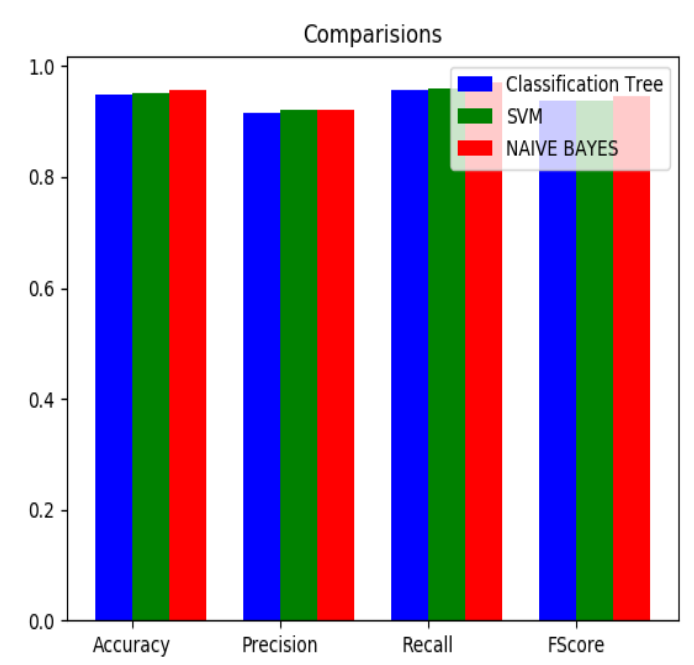

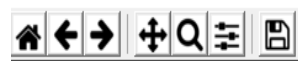

Before experimenting of the dataset i.e. using the dataset. The dataset is inspecting initially to get a knowledge on the total number of tuples the dataset contain. The initial step after loading the dataset is to inspect the data.Then we will preprocess the dataset to remove the unwanted data. Next we are training the classifier with negative reviews dataset and positive reviews dataset.Finally we are detecting the test reviews are whether genuine or fake.

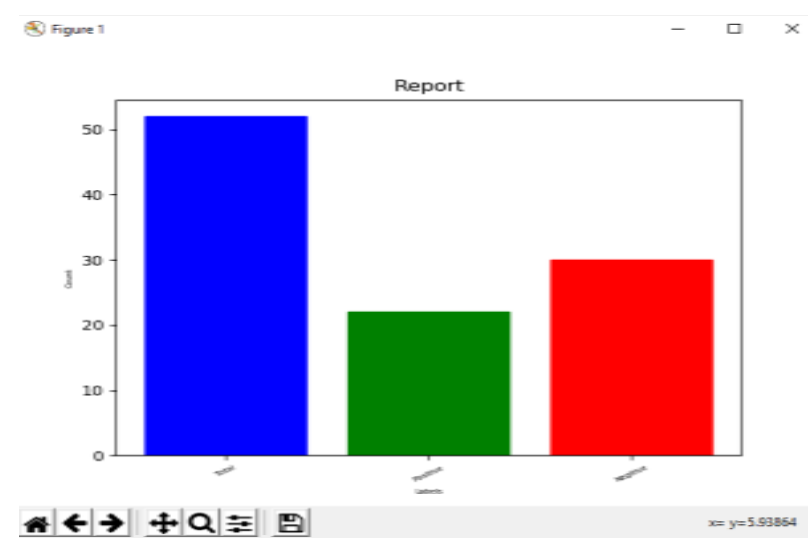

To the above dataset we applied naive bayes and decision tree algorithms and naive bayes is showing more better accuracy comparatively decision tree.And also we are showing the results in barchart.
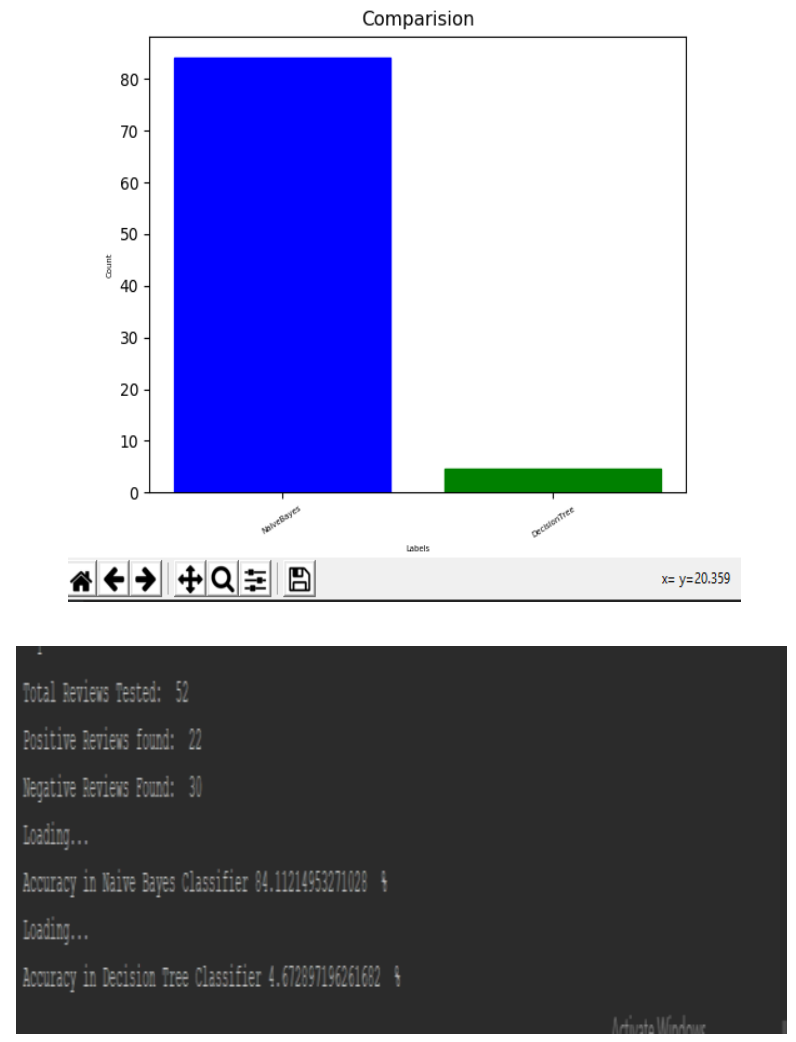

\section{CONCLUSIONS AND FUTURE SCOPE}

From the files analyzed it can be concluded that most of the work has really been done using classification Machine Leaning strategies like Naive bayes,SVM,Decision Tree etc. For discovering network, declarations can be associated by methods for gathering spammer qualities, (for example, the prompted trademark in) notwithstanding surveys with most prominent practical likeness dependent on meta course idea are depicted as areas. In this paper, we plan to classify evaluations as positive, undesirable as well as likewise spam testimonies by generating a social networks network equivalent system in addition to providing communication in between people in it. Machine along with deep learning techniques have been used for all applications as well as are increasingly being adopted likewise for spam review detetion, it is, therefore, vital to check when and additionally which type of formulas may attain suitable outcomes.

Our future work will focus on how to improve the accuracy by using the latest models in the field of spam review detection and classification. The entirety ML framework is executed underway condition and completely robotized from spam detection, day by day model reviving, to constant scoring, which incredibly improve proficiency and upgrade endeavor chance identification furthermore, the executives.Even We can implement artificial intelligence and deep learning to improve the more accuracy. 


\section{REFERENCES}

1. Piera. E.-P. Lim, V.-A.Nguyen, N. Jindal, B. Liu, and H, W. Lauw.Detecting product review spammers using rating behaviors.In ACM CIKM, 2010.

2. A. Mukherjee, A. Kumar, B. Liu, J. Wang, M. Hsu, M Castellanos, and R. Ghosh. Spotting opinion spammers using behavioral footprints.In ACM KDD, 2013.

3. S. Xie, G. Wang, S. Lin, and P. S. Yu. Review spam detection via temporal pattern discovery. In ACM KDD, 2012.

4. G. Wang, S. Xie, B. Liu, and P. S. Yu. Review graph based online store review spammer detection. IEEE ICDM, 2011.

5. Y. Sun and J. Han. Mining Heterogeneous Information Networks; Principles and Methodologies, In ICCCE, 2012.

6. A. Mukerjee, V. Venkataraman, B. Liu, and N. Glance. What Yelp Fake Review Filter Might Be Doing?, In ICWSM, 2013.

7. S. Feng, L. Xing, A. Gogar, and Y. Choi.Distributional footprints of deceptive product reviews.In ICWSM, 2012.

8. A. j. Minnich, N. Chavoshi, A. Mueen, S. Luan, and M. Faloutsos. Trueview: Harnessing the power of multiple review sites. In ACM WWW, 2015.

9. B. Viswanath, M. Ahmad Bashir, M. Crovella, S. Guah, K. P. Gummadi, B. Krishnamurthy, and A. Mislove. Towards detecting anomalous user behavior in online social networks.In USENIX, 2014.

10. H. Li, Z. Chen, B. Liu, X. Wei, and J. Shao. Spotting fake reviews via collective PU learning.In ICDM, 2014.

11. Kayiram Kavitha, Polsani Rajashree Rao, Sreeja Tummala, Gajarla Vasavi, and Dr.R.Gururaj, Dual Tree Data Routing Scheme for Wireless Sensor Networks, Third International Conference on Advances in Information Technology and Mobile Communication, AIM -2013, 26-27, April 2013, Bangalore, India.

12. Kayiram Kavitha, Vinod Pachipulusu, Sreeja Thummala, R.Gururaj. Article: Energy Efficient Query Processing for WSN based on Data Caching and Query Containment, in International Journal of Computer Applications, Vol. 89, no. 19, Page no. 4-8, March 2014 , Published by Foundation of Computer Science, New York, USA.

13. Sharma D, Kavitha K, Gururaj R. Article: Estimating Node Density for Redundant Sensors in Wireless Sensor Network, in International Journal of Sensor Networks and Data Communications, Vol.4, Issue 2 no.127, November 2015, Published by OMICS International.

14. R.V.S.Lalitha, K.Kavitha, N.V.Krishna Rao, G.Rama Mounika, V.Sandhya, Smart surveillance using Smart doorbell, International Journal of Innovative Technology and Exploring Engineering, Volume-8, Issue-8 June, 2019.

\section{AUTHORS PROFILE}

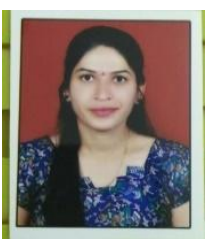

R.Mounika is pursuing her post-graduation in the department of Computer Science and Engineering of Gokaraju Rangaraju Institute of Engineering and Technology (GRIET), Hyderabad, Telangana, India.

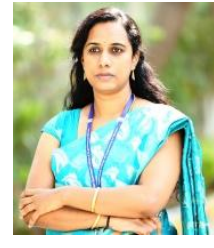

Dr. Kayiram Kavitha obtained her $\mathrm{PhD}$ from BITS-Pilani. She has 14 years teaching experience in BITS-Pilani, Hyderabad Campus and other institutions with exceeding academic standards and enhancing overall curriculum. Her research interests include Wireless Sensor Networks, Mobile computing, Security in IoT, QoS in MANETs.

Dr. R V. S. Lalitha is currently working as Professor in the Department of CSE, Aditya College of Engineering and Technology, Surampalem, Kakinada., AP, India. Her areas of interest include Vehicular Ad hoc Networks, Data mining, and Mobile computing. 